\title{
Recurrent tumor involving a diverticulum after colonic endoscopic submucosal dissection successfully resected by the double-tunnel method
}
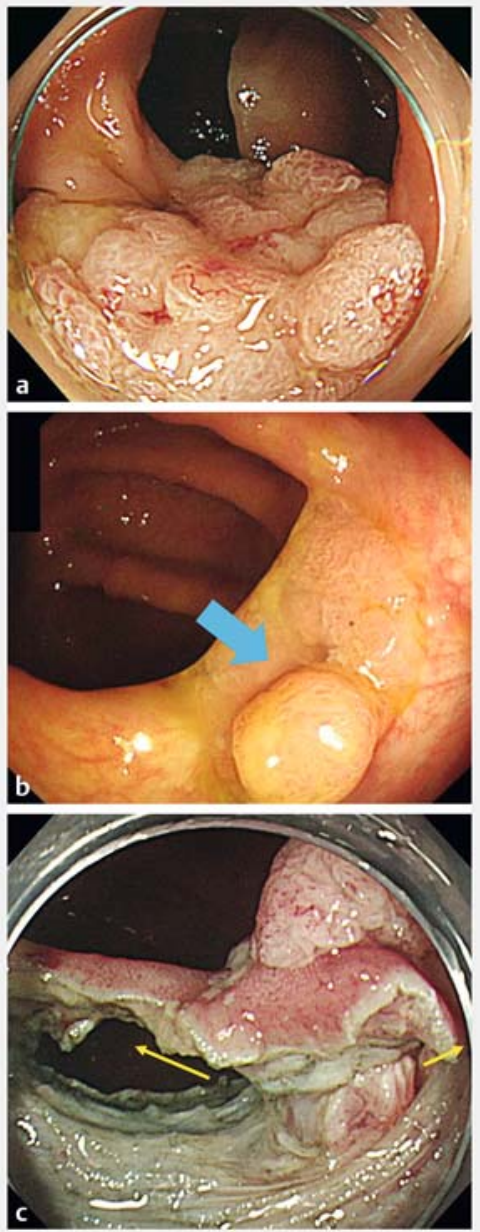

- Fig. 1 Endoscopic images showing: a the initial laterally spreading tumor measuring $30 \mathrm{~mm}$ in diameter in the ascending colon; $\boldsymbol{b}$ recurrent tumor involving a colonic diverticulum (blue arrow) after endoscopic treatment (a scar from this treatment is seen on each side of the lesion); $c$ the two different tunnels on each side of the diverticulum (yellow arrow), which allowed good traction to be maintained and an appropriate dissection line to be identified.

Repeat endoscopic treatment is challenging for lesions that recur after endoscopic resection and for lesions involving a diverticulum because of the severe fibrosis surrounding such lesions $[1,2]$.

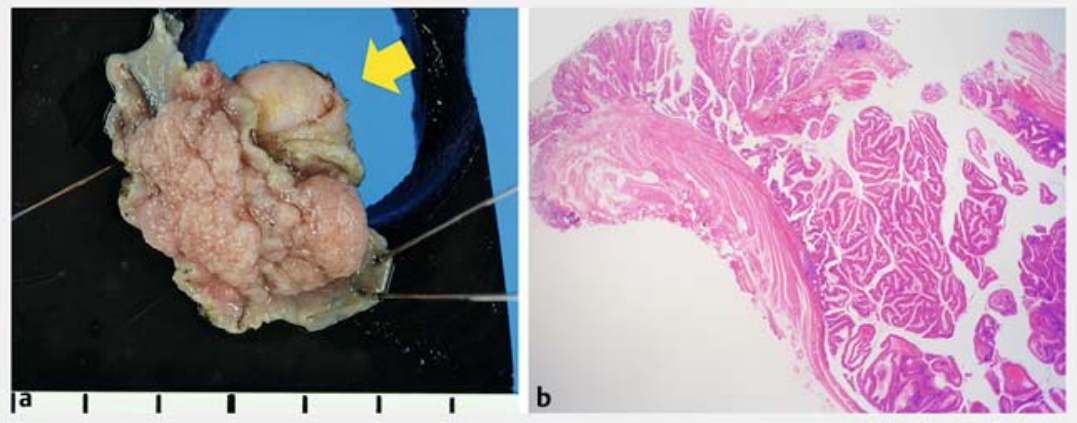

- Fig. 2 Histopathological appearances of the resected tumor: a macroscopic image (yellow arrow is pointing to the diverticulum); b microscopic image, showing an intramucosal carcinoma.

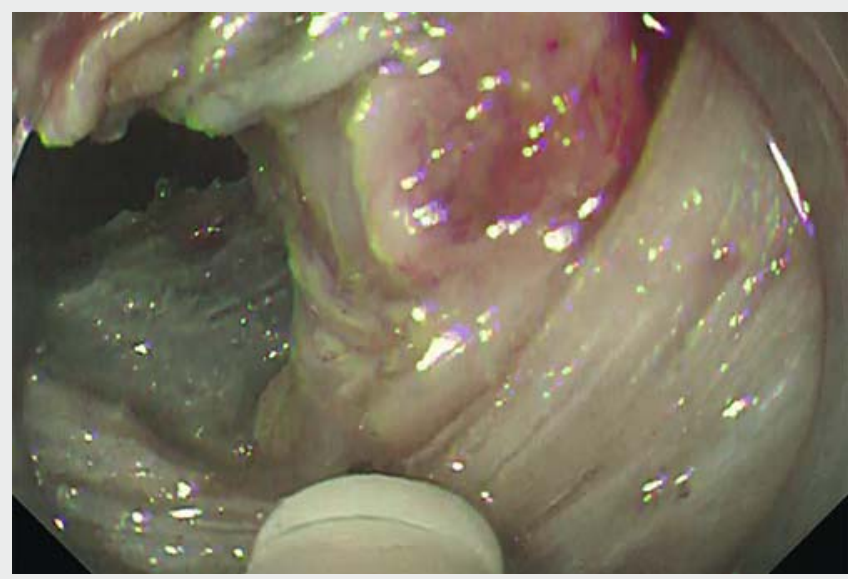

Video 1 Colorectal endoscopic submucosal dissection using the double-tunnel method, allowing efficient and safe resection of a recurrent lesion arising from a diverticulum and surrounded by severe fibrosis.

We report the case of a tumor involving a diverticulum that recurred after colonic endoscopic submucosal dissection (ESD) and was successfully resected by the double-tunnel method.

A 72-year-old woman was diagnosed 2 years ago as having a laterally spreading tumor (LST) in her ascending colon measuring $30 \mathrm{~mm}$ in diameter ( $>$ Fig.1a), which her previous doctor had attempted to treat by ESD. After making the circum- ferential incision, he faced a diverticulum during the process of dissection and discontinued the procedure. He cauterized the rest of the tumor.

This time, the patient was referred to our hospital for treatment of a recurrence of the diverticular tumor after the attempted ESD ( $\triangleright$ Fig. $1 \mathbf{b}$ ). The tumor arose in a diverticulum and was surrounded by fibrosis, so we expected that lifting of the lesion after local injection would not be 
possible because of the lack of a soft submucosal layer. We had previously reported that the double-tunnel method is useful for lesions associated with severe fibrosis [3]. In addition to dealing with the fibrosis, we applied this method to apply traction to the diverticular area to pull the tumor out of the muscle layer into the lumen ( $\triangleright$ Video 1 ). This technique allows good traction to be maintained and an appropriate dissection line to be identified, even in situations involving severe fibrosis in a diverticulum ( $\mathbf{F i g} \mathbf{1} \mathbf{c}$ ). Using this method, we successfully performed en bloc resection of the tumor. The patient recovered without incident. Histological examination revealed an intramucosal carcinoma and confirmed the curative resection ( $>$ Fig. 2 ).

Use of the double-tunnel method enables safe en bloc resection of lesions with fibrosis, even of those arising in diverticula.

Endoscopy_UCTN_Code_CPL_1AJ_2AD

\section{Competing interests}

The authors declare that they have no conflict of interest.
The authors

Marie Kurebayashi ${ }^{1}$, Ken Ohata ${ }^{1}$, Hideyuki Chiba $^{2}$, Maiko Takita ${ }^{1}$, Takashi Muramoto', Fumiki Toriumi ${ }^{3}$, Eiji Sakai ${ }^{4}$

1 Department of Gastroenterology, NTT Medical Center Tokyo, Tokyo, Japan

2 Department of Gastroenterology, Omori Red Cross Hospital, Tokyo, Japan

3 Department of Surgery, Tokyo Saiseikai Central Hospital, Tokyo, Japan

4 Department of Gastroenterology, Yokohama Sakae Kyosai Hospital, Tokyo, Japan

Corresponding author

\section{Ken Ohata, MD, PhD}

Department of Gastrointestinal Endoscopy, NTT Medical Center Tokyo, 5-9-22 Higashigotanda Shinagawa-ku, Tokyo 141-8625, Japan

Fax: +81-3-3448-6541

ken.ohata1974@gmail.com

\section{References}

[1] Hayashi N, Tanaka S, Nishiyama S et al. Predictors of incomplete resection and perforation associated with endoscopic submucosal dissection for colorectal tumors. Gastrointest Endosc 2014; 79: 427-435

[2] Kim ES, Cho KB, Park KS et al. Factors predictive of perforation during endoscopic submucosal dissection for the treatment of colorectal tumors. Endoscopy 2011; 43: 573-578
[3] Chiba H, Tachikawa J, Kurihara D et al. Safety and efficacy of simultaneous colorectal ESD for large synchronous colorectal lesions. Endosc Int Open 2017; 5: E595-E602

Bibliography

Endoscopy 2021; 53: E185-E186

DOI 10.1055/a-1230-3203

ISSN 0013-726X

published online 2.9.2020

(c) 2020. Thieme. All rights reserved.

Georg Thieme Verlag KG, Rüdigerstraße 14, 70469 Stuttgart, Germany

\section{ENDOSCOPY E-VIDEOS}

https://eref.thieme.de/e-videos

口回 Endoscopy E-Videos is a free access online section, reporting 自祀: on interesting cases and new

techniques in gastroenterological endoscopy. All papers include a high quality video and all contributions are freely accessible online.

This section has its own submission website at https://mc.manuscriptcentral.com/e-videos 